\title{
Research on the Impact of FDI on China's Industrial Agglomeration -- Based on the Empirical Analysis of Regional Data \\ Panpan Ge
}

\author{
No.99, Shangda road, Baoshan District, Shanghai, China \\ 1319791472@qq.com
}

\begin{abstract}
Keywords: FDI; China's industrial agglomeration; Factors of agglomeration; Empirical analysis; Regional level
\end{abstract}

\begin{abstract}
As for China, since the reform and open, domestic industries have shown a quite obvious tendency of agglomeration, which catches the attention of both economic researchers and policy makers. However, although it has been proved by the previous researches that China's opening up to the outside world promoted domestic industrial agglomeration; most of the literature focused on the importance of decreasing trade costs to domestic industrial agglomeration, the importance of FDI was always ignored. This is also the main research purpose of this article, from the aspects of FDI to analyze its influence on industrial agglomeration. As follows is the research method of the paper, using the panel data of the 30 Chinese provinces industrial in 2005-2015, and then constructing the econometric model, then testing the effects of FDI on the China's industrial agglomeration. The empirical results show that FDI significantly promoted the China's industrial agglomeration. As follows are the research conclusions of the paper, FDI act on Chinese economic growth and regional disparity adjustment, which means that Chinese government should make rational use of FDI, to further promote the agglomeration of China's industrial, and effectively promote the economic growth and regional inequality.
\end{abstract}

\section{Introduction}

Many scholars pay attention to this problem, the relationship between FDI and industrial agglomeration is discussed. In the field of international direct investment researches, industrial concentration is generally regarded as one of the important factors influencing the FDI location selection, some scholars of China's empirical analysis to support this view; researches on the new economic geography field depends on the trade cost reduction as the investigation object, analyzing the influence of the economic integration to domestic industry distribution. However, economic integration lead to the concentration or dispersion, the conclusion is inconsistent, China empirical analysis of some scholars affirmed the positive elements of opening to the outside world is a domestic industry agglomeration. However, the research of the influence of FDI on China's industrial cluster is still rare. Therefore, the existing basic studies demonstrate that the industrial concentration is one of the influence factors of FDI location choice in China, whether on FDI promotes the industry cluster of China, how to promote the industrial agglomeration, is not yet solved.

There are two main research contributions of this paper: first, bring the factors of FDI into the influencing factors of industry cluster, and to explore the influence of FDI on China's industrial agglomeration mechanism, striving to develop industrial agglomeration theory research perspectives. Second, the empirical studying the effect of FDI on China's industrial agglomeration, reasonable utilization of foreign capital to promote industrial agglomeration to China put forward policy suggestions. Existing research basic affirmed the China's industrial agglomeration is one of the important factor to attract FDI location choice, however, specifically for the empirical analysis of FDI influences on industrial agglomeration is still relatively rare. 


\section{Literature Reviews at Home and Abroad}

Research on industrial agglomeration content is relatively rich, but the change trend of the main areas to focus on agglomeration, externality, influence factors, agglomeration and economic integration, and economic growth and regional gap, and element flow, and the environmental protection and so on. Below will be based on this topic from two aspects: theoretical and empirical carding the related literatures.

Relevant Reviews of Theoretical Researches. Theory research mainly related literature of general theory of industrial agglomeration. The study of the theory of the industrial agglomeration in classical economics analysis of the location problem. Krugman (1991) set up the core-periphery model, realized in the monopoly competition market, such as transportation costs and scale increasing return conditions, the economic activities in the role of agglomeration and dispersion forces spatial distribution of the analysis of the equilibrium, fundamentally changed the state of the edge of the industry cluster research in the field of economics, making it the economic theory research hot spot in recent 20 years. Shijie Li, Guoliu Hu, Jian Gao (2014), based on existing literature, combed the geography economics and new economic geography about the formation and evolution of industrial agglomeration theory [1].

Relevant Reviews of empirical Researches. In recent years, domestic and foreign scholars from different angles of industrial concentration were studied. Below will be from the industrial concentration degree and the change trend, the factors influencing industrial agglomeration and FDI effect on industrial agglomeration Angle carding the related literatures.

Industrial concentration degree and the change trend of research. Foreign scholars' earlier studies of industrial agglomeration. Leahy (2010) the use of EG and MS index for manufacturing agglomeration of Australia from 1994 to 1997 is calculated. Chinese scholars study confirmed the existence of Chinese industrial agglomeration. Renfa Yang (2013) from the new economic geography and spatial agglomeration theory perspective, the use of 2003-2010 in China more than 269 local and city as sample, measuring the degree of industrial concentration[2]; Hai-gong Yuan, Hua Zhang, Hongyong Ceng (2014), select the DO index data of micro enterprise of Beijing in the different space every degree of refining industry measure research of industrial cluster[3]; Dongwei Wen, Guoming Xian (2014), using the data of 1998-2009 on the level of manufacturing enterprises in China, from three aspects: provincial, city and county to investigate the extent of the manufacturing industry agglomeration and its evolution trend [4].

Research in the impacting factors of industrial agglomeration. Baldwin (2010), such as using Canadian manufacturing enterprise level in 1989-1999 panel data on the influence factors of industrial agglomeration and cluster externalities of the geographical scope of radiation were analyzed. Domestic scholars discussed on this issue have also made great progress. Xiufeng Fan, Xiaoqin Kang (2013) choose 28 manufacturing industry of Shanxi province in 2013-2011 as sample, using location entropy index and spatial Gini coefficient to studying the factors affecting the empirical analysis[5]; Yu Dai (2013) using the location entropy of Hunan province during 2004-2009 to measure the cultural industry agglomeration and the factors of influence study[6]; Meng Wang, Youxin Wang (2015) using 35 large and medium cities in China in 2003-2011 data, the influence factors of urban cultural industry agglomeration[7].

Research of relationship between FDI and industrial agglomeration. Many foreign scholars early to notice that the interaction between the two. Bertarelli (2009) to Italy as investigation object, and found that the department and regional specialization level played an important role in attracting FDI. A large number of literature of our country basically concluded foreign direct investment has a positive influence on China's industrial agglomeration. Pu-yang Sun, Shuai Han, Shujing Jin (2012)using the 2012-2008 panel data of 288 cities in China empirical analysis on industrial convergence of manufacturing and service industries the impact of foreign direct investment [8]; Gangming Chen (2012), selected the data of 2003 - 2010 the empirical analysis the relationship between industrial agglomeration and FDI [9]; Ming $\mathrm{Xu}$ (2013) using the panel data of manufacturing industry in Shanxi Province during 2006-2010, the empirical analysis of the influence of FDI in industry cluster in Shanxi province [10]; Yongchao Song (2016) based on the 
panel data of 29 provinces from 2004 to 2013, using spatial econometric model to study the FDI and industrial agglomeration and the relationship between the pattern of economic development [11].

\section{The Empirical Research of FDI on China's Industrial Agglomeration}

The Correlation between FDI and China's Industrial Agglomeration in Regional Level. Regional level of FDI and industrial agglomeration correlation investigation method and the method of similar industry level: calculation of regional industrial agglomeration and FDI penetration are average, according to the list of results and make a scatter plot. According to the existing research, regional FDI penetration to FDI proportion of regional GDP, FDI and GDP data from 2005-2015 China statistical yearbook, not including Tibet. The calculation results see Table 1 and Fig. 1.

Table 1 FDI and China's industrial agglomeration in regional level (2005-2015)

\begin{tabular}{|c|c|c|c|c|c|}
\hline Province & $\begin{array}{c}\text { The average } \\
\text { proportion of } \\
\text { industrial }\end{array}$ & $\begin{array}{c}\text { The average } \\
\text { proportion of } \\
\text { FDI/GDP }\end{array}$ & Province & $\begin{array}{c}\text { The average } \\
\text { proportion of } \\
\text { industrial }\end{array}$ & $\begin{array}{c}\text { The average } \\
\text { proportion of } \\
\text { FDI/GDP }\end{array}$ \\
\hline Beijing & 0.0192 & 0.0454 & Henan & 0.0615 & 0.0097 \\
\hline Tianjin & 0.0226 & 0.0978 & Hubei & 0.0403 & 0.0252 \\
\hline Hebei & 0.0596 & 0.0153 & Hunan & 0.0307 & 0.0223 \\
\hline Shanxi & 0.0239 & 0.0098 & Guangdong & 0.1245 & 0.0667 \\
\hline Inner & 0.0188 & 0.0266 & Guangxi & 0.0172 & 0.0129 \\
\hline Mongolia & 0.0493 & 0.0554 & Hainan & 0.0020 & 0.0667 \\
\hline Liaoning & 0.0183 & 0.0235 & Chongqing & 0.0148 & 0.0160 \\
\hline Jilin & 0.0371 & 0.0259 & Sichuan & 0.0355 & 0.0109 \\
\hline Heilongjiang & 0.0498 & 0.0613 & Guizhou & 0.0088 & 0.0086 \\
\hline Shanghai & 0.1124 & 0.0692 & Yunnan & 0.0166 & 0.0054 \\
\hline Jiangsu & 0.0795 & 0.0365 & Shanxi & 0.0189 & 0.0145 \\
\hline Zhejiang & 0.0274 & 0.0142 & Gansu & 0.0090 & 0.0029 \\
\hline Anhui & 0.0380 & 0.0783 & Qinghai & 0.0026 & 0.0272 \\
\hline Fujian & 0.0181 & 0.0351 & Ningxia & 0.0030 & 0.0147 \\
\hline Jiangxi & 0.1130 & 0.0357 & Xinjiang & 0.0116 & 0.0020 \\
\hline Shandong & & & & & \\
\hline
\end{tabular}

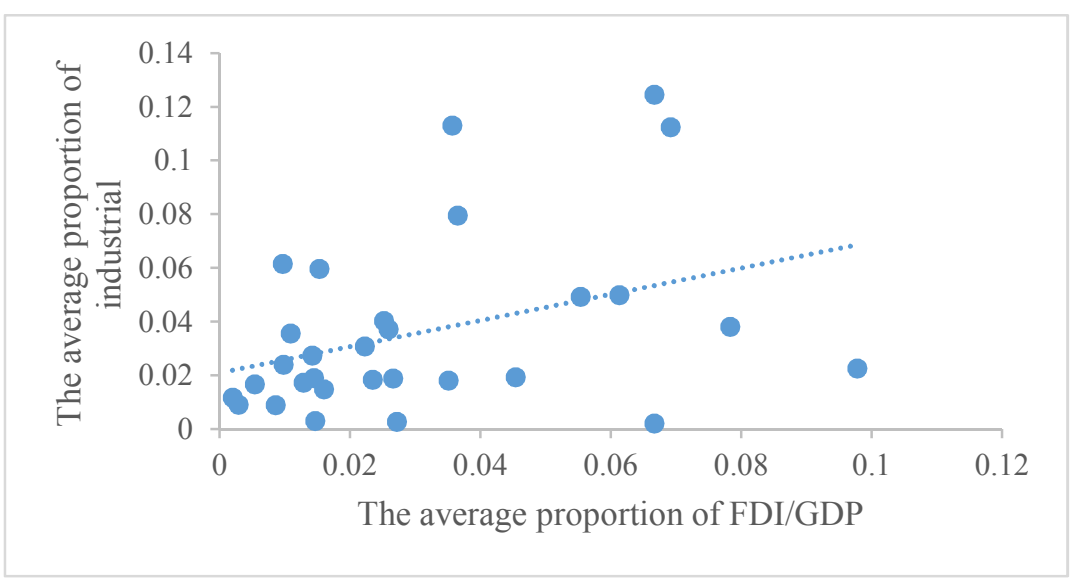

Figure 1. The scatter plot of the relationship between the average proportion of industrial and the average proportion of FDI/GDP 
According to Table 1, the average proportion of FDI/GDP higher areas, such as Jiangsu, Zhejiang, Fujian, Guangdong, Shandong, Shanghai, etc., the average industrial proportion is higher; lower average using the pinch region, such as Gansu, Xinjiang, Guizhou, and the industrial average proportion is low. As the Fig. 1 shows that, there is a correlation between the average proportion of industrial and the average proportion of FDI/GDP.

Variable Selection and Model Building. According to Table 2, there are the selected factors of China's industrial region agglomeration, which are based on the industry cluster theory and related literature classic.

Table 2 The variable and the description

\begin{tabular}{|c|c|}
\hline The variable & Variable description \\
\hline FDI & Measured by the average proportion of FDI/GDP. \\
\hline $\begin{array}{c}\text { Local } \\
\text { Protection }\end{array}$ & $\begin{array}{l}\text { Measured by the proportion of the regional enterprise income tax and the regional } \\
\text { finance income. }\end{array}$ \\
\hline $\begin{array}{l}\text { Market } \\
\text { Potential }\end{array}$ & $\begin{array}{l}M P_{i}=\sum_{j \neq i}\left(\frac{G D P_{j}}{D_{i j}}+\frac{G D P_{i}}{D_{i i}}\right), \mathrm{i}, \mathrm{j} \text { as province, } \mathrm{MP}_{\mathrm{i}} \text { as domestic market potential of } \mathrm{i} \\
\text { province, } \mathrm{GDP}_{\mathrm{j}} \text { as GDP of } \mathrm{j} \text { province, GDP } \mathrm{i} \text { as GDP of } \mathrm{i} \text { province, } \mathrm{D}_{\mathrm{ij}} \text { as the shortest } \\
\text { road distance between } \mathrm{i} \text { and } \mathrm{j}, \mathrm{D}_{\mathrm{ii}} \text { as the internal distance of } \mathrm{I} \text { province, the } \\
\text { calculation method as } D_{i i}=\frac{2}{3} \sqrt{\frac{s_{i}}{\pi}}, \mathrm{S}_{\mathrm{i}} \text { as the geographical area of I province. }\end{array}$ \\
\hline Labor Cost & $\begin{array}{c}\text { Measured by the relative wage levels, namely the regional average wage and the } \\
\text { ratio of per capita GDP. }\end{array}$ \\
\hline $\begin{array}{l}\text { Human } \\
\text { Capital }\end{array}$ & $\begin{array}{l}\text { Measured by the college degree or above in population and area ratio of the total } \\
\text { population. }\end{array}$ \\
\hline $\begin{array}{c}\text { Natural } \\
\text { Endowment }\end{array}$ & Measured by the proportion of the regional mining industry output value and GDP. \\
\hline $\begin{array}{l}\text { Crowded } \\
\text { Cost }\end{array}$ & Measured by the capital city land per capita and the ratio of per capita GDP. \\
\hline$\varepsilon_{i j}$ & The random disturbance item. \\
\hline
\end{tabular}

Econometric model set is as follows:

$A g g_{i j}=\alpha+\beta_{1} \mathrm{FDI}_{\mathrm{ij}}+\beta_{2}$ Local Protection $_{\mathrm{ij}}+\beta_{3}$ Market Potential $_{\mathrm{ij}}+\beta_{4}{\text { Labor } \text { Cost }_{\mathrm{ij}}+}+$

$\beta_{5}$ Human Capital $_{\mathrm{ij}}+\beta_{6}$ Natural Endowment $_{\mathrm{ij}}+\beta_{7}$ Crowded Cost $_{\mathrm{ij}}+\varepsilon_{\mathrm{ij}}$

In the Eq. $1, \mathrm{I}$ for provinces, $\mathrm{j}$ for the year, $\alpha$ as constant, $\varepsilon_{i j}$ as the error term.

Measurement Results and the Result Analysis. By applying the Eviews6.0 software in 30 provinces in 2005-2015 panel data regression estimation, estimation results through Haussmann test and $\mathrm{F}$ test, select fixed effects model. Table 3 reports the district level seven influencing factors of China's industrial cluster regression results.

Table 3 The regression results of the influence factor of industrial cluster

\begin{tabular}{|c|c|c|c|}
\hline The variable & The coefficient & The variable & The coefficient \\
\hline FDI & $\begin{array}{c}0.314803^{* * *} \\
(0.020058)\end{array}$ & Natural Endowment & $\begin{array}{c}0.072458^{* * *} \\
(0.011101)\end{array}$ \\
\hline Local Protection & $\begin{array}{c}0.124159^{* * *} \\
(0.033751)\end{array}$ & Crowded Cost & $\begin{array}{c}0.011633^{* * *} \\
(0.006142)\end{array}$ \\
\hline Market Potential & $\begin{array}{c}0.054015^{* * *} \\
(0.008869)\end{array}$ & $\alpha$ & $\begin{array}{c}0.027944^{* * *} \\
(0.004959)\end{array}$ \\
\hline Labor Cost & $\begin{array}{c}-0.211255^{* * *} \\
(0.037624)\end{array}$ & $\mathrm{R}^{2}$ & 0.839368 \\
\hline Human Capital & $\begin{array}{c}-0.192853^{* * *} \\
(0.037624)\end{array}$ & \multirow{2}{*}{ AdjustR $^{2}$} & 0.829882 \\
\hline Number of Samples & 300 & & \\
\hline
\end{tabular}


Note: $* * *$ mean significant at $1 \%$ level, mean significant at $5 \%$ level, $* * *$ significant at $10 \%$ level; the value of standard deviation coefficient of the brackets.

All in all, according to the industrial cluster to regional level regression analysis on the influencing factors of FDI, local protection, market potential, congestion cost, natural endowment plays a positive role of industrial agglomeration, and labor costs to industrial agglomeration has negative effects at the $1 \%$ level. This also expectations largely consistent with the theory of above.

\section{Conclusion}

This research about the impact of FDI on Chinese industrial agglomeration, the main draw the following conclusions:

First, industrial agglomeration is the concentration of industry in a specific geographical scope. The geographic concentration of industrial agglomeration can be said a single industry, can also be said of multiple industry geographic copolymerization; The geographic scope of an agglomeration but can small, which can be a city jurisdiction, also can be made up of several provinces.

Second, the location choice of FDI in China, will be able to attract other location choice of FDI and domestic enterprises to make similar, so as to promote China's industrial agglomeration. At the same time, China's industrial agglomeration will also impact on FDI.

Third, FDI has influence on China's industrial agglomeration, role in China's economic growth and regional gap adjustment, this means that the Chinese government should reasonable use of FDI, further promote China's industrial agglomeration, and accelerate the process of China industrial agglomeration to disperse, so as to effectively promote the economic growth while region, narrow the gap.

\section{Reference}

[1] Shijie Li, Guoliu Hu, Jian Gao. In transition period of China's industrial agglomeration evolution: theory review, research progress and explorative thinking [J]. Management of the world, 2014, (04):165-170.

[2] Renfa Yang. Industrial agglomeration and regional wage gap, based on the empirical study of 269 cities in China [J]. Management of the world, 2013, (08):41-52.

[3] Haihong Yuan, Hua Zhang, Hongyong Zeng. Measure of industrial concentration and its dynamic change, based on the research of Beijing enterprise micro data [J]. China industrial economy, 2014, (03):3-31.

[4] Dongwei Wen, Guoming Xian. The degree of China's manufacturing industry agglomeration and its evolution trend: from 1998 to 2009 [J]. Journal of world economy, 2014, (3):3-31.

[5] Xiufeng Fan, Xiaoqin Kang. Shanxi manufacturing industrial concentration degree is calculated and its influencing factors of the empirical analysis [J]. Journal of economic geography, 2013, (9): $115-119+160$.

[6] Yu Dai. Hunan culture industry agglomeration and its influencing factors research [J]. Journal of economic geography, 2013, (4):114-119.

[7] Meng Wang, Youxin Wang. The influence factors of urban cultural industry cluster research evidence from 35 large and medium cities [J]. Journal of Jiangxi University of finance and economics, 2015, (01):12 to 20.

[8] Puyang Sun, Shuai Han, Shujing Jin. Industrial agglomeration of foreign direct investment (FDI) impact analysis, based on the comparative study of the service industry and manufacturing [J]. Journal of quantitative technical economics, 2012, (9):40-57.

[9] Gangming Chen. Study on the relationship between the FDI and industrial agglomeration [D]. Chongqing University, 2012.

[10] Ming Xu. FDI effect on industrial agglomeration in Shanxi research [D]. Lanzhou business school, 2013. 
[11] Yongchao Song. FDI and industrial agglomeration and the pattern of economic development, based on the research of panel data econometric model space [J]. Journal of business research, 2016, (14):163-165. 